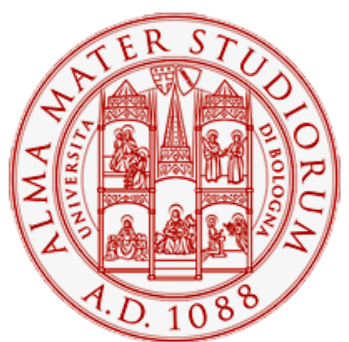

Alma Mater Studiorum - Università di Bologna DEPARTMENT OF ECONOMICS

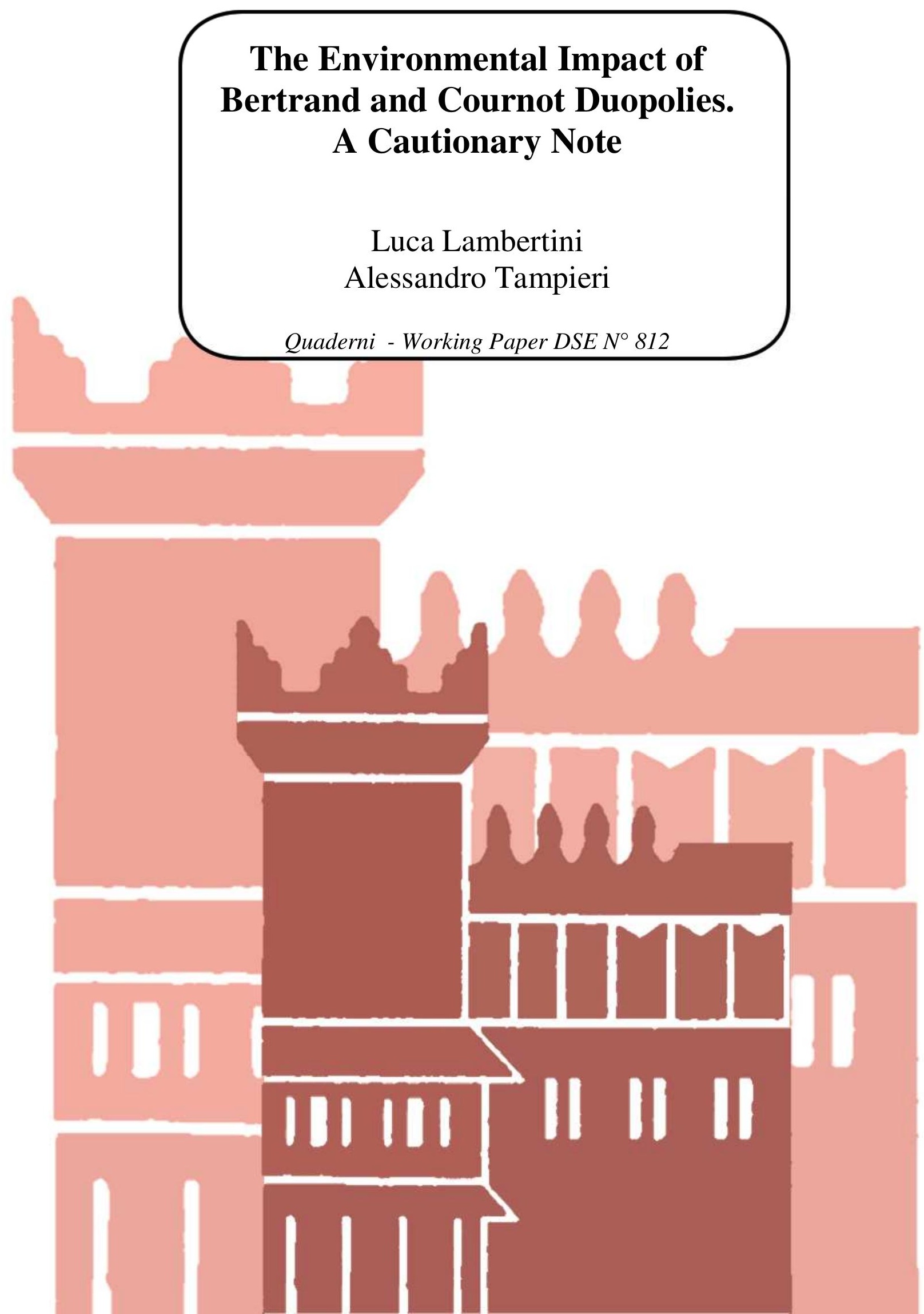




\title{
The Environmental Impact of Bertrand and Cournot Duopolies. A Cautionary Note
}

\author{
Luca Lambertini* $^{*} \quad$ Alessandro Tampieri ${ }^{\dagger}$
}

February 15, 2012

\begin{abstract}
We compare a Bertrand with a Cournot duopoly in a setting where production is polluting and exploits natural resources, and firms bear convex production costs. We adopt Dastidar's (1995) approach, yielding a continuum of Bertrand-Nash equilibria ranging above marginal cost pricing also, to show that softening price competition may lead to a lower output production in a Bertrand rather than a Cournot industry. The market structure bringing about the lowest output determines the highest social welfare, given the fact that the negative environmental effects of production more than offset the gain in consumer surplus.
\end{abstract}

JEL Numbers: L13, L51, Q55, Q58.

Keywords: Intensity of competition, natural resources exploitation, pollution, Bertrand or Cournot industries.

*Department of Economics, University of Bologna. Strada Maggiore 4540125 Bologna, Italy. Email: luca.lambertini@unibo.it.

${ }^{\dagger}$ Department of Economics, University of Bologna. Strada Maggiore 4540125 Bologna, Italy. Email: alessandro.tampieri@unibo.it. 


\section{Introduction}

In the theory of the oligopoly, it is common knowledge that price rather than quantity competition delivers a higher amount of output in an industry, leading in turn to a higher social welfare. This wisdom may not hold in the case that negative externalities, such as natural resources exploitation and polluting emission, take place in the industry considered. Moreover, not all the production cost structures necessarily imply a larger production with Bertrand competition.

In this note we discuss this argument in a duopoly setting where production entails both natural resources exploitation and pollution, and firms bear a convex cost function. Indeed, Dastidar (1995) shows that, under Bertrand competition and convex production costs, there is a continuum of Nash equilibria, ranging also above marginal cost pricing. In particular, the occurring equilibrium will depend on the intensity of price competition. In line with this approach, we establish that the industry output can be smaller with

price rather than quantity competition, provided that the intensity of price competition is sufficiently low.

Given the environmental impact of production, a trade-off emerges between resource utilisation and pollution on the one hand and consumer surplus on the other, with the first effect more than offsetting the second one. Therefore, the market structure yielding the highest social welfare is the one that entails the lowest quantity produced.

\section{The model}

We consider two firms in an industry, producing the same homogeneous good, and having symmetric and convex production costs:

$$
C=c q^{2}
$$


where $q$ is the quantity produced by each firm and $c>0$. Let the inverse demand be linear:

$$
p=1-Q,
$$

where $Q=2 q$. Each firm profits are:

$$
\pi=p q-c q^{2} .
$$

The production of the final output exploits some natural resources $X=$ $\bar{X}-w Q$, where $w>0$ is the marginal exploitation. Also, production goes along with a negative environmental externality $E=g Q^{2}$, where $g>0$ represents the marginal polluting intensity of output. Consumer surplus is measured by $C S=Q^{2} / 2$. Social welfare is defined as the sum of industry profits, consumer surplus and the natural resource, minus pollution:

$$
W=2 \pi+C S+X-E=Q\left(p-c Q+\frac{Q}{2}-w-g Q\right)+\bar{X} .
$$

\section{Results}

In what follows, we will compare Bertrand with Cournot competition to show that the latter may have a stronger impact on environment. We start by examining the equilibrium quantity under Bertrand competition.

According to Dastidar (1995), if firms have symmetric convex costs and compete à la Bertrand, the Nash equilibrium is necessarily non-unique. In particular, a pure-strategy Nash equilibrium is characterised by both firms setting the same price $p^{*}$, which is bounded by two thresholds $p^{a v c} \leq p^{*} \leq p^{u}$. The lower bound $p^{a v c}$ (the superscript avc stands for average variable cost) equals average variable costs, letting firms be indifferent between either producing at $p^{*}$ or producing nothing at all. The upper bound $p^{u}$ (with superscript $u$ standing for undercutting) is the price at which firms are indifferent between choosing price $p^{u}$, and marginally undercutting it in order to capture 
the entire demand at $p^{u}$.

In this setting, the level of $p^{a v c}$ is given by equating the inverse demand function to the average variable cost:

$$
1-2 q=c q
$$

then solving for $q$ and substituting in the demand function we obtain:

$$
p^{a v c}=\frac{c}{2+c} .
$$

The upper bound of the equilibrium price obtains by imposing indifference between duopoly profits (3) and the monopoly profits generated by undercutting:

$$
p q-c q^{2}=2 p q-4 c q^{2}
$$

Solving for $p$, we obtain

$$
p^{u c}=\frac{3 c}{2+3 c} .
$$

Finally, by equating the inverse demand function to the marginal cost, solving for $q$ and substituting into $p$, we obtain the price equal to marginal cost:

$$
p^{m c}=\frac{c}{1+c},
$$

where the superscript $m c$ stands for marginal cost pricing. The continuum of Nash equilibria can be represented by the following expression: ${ }^{1}$

$$
p^{*}=\frac{c}{2+c-\alpha} .
$$

Parameter $\alpha$ represents the relative intensity of price competition between firms. Note that, when $\alpha=0$, in equilibrium price equals average variable cost; $\alpha=1$ corresponds to the Bertrand reference case in which price is equal to marginal cost, while at $\alpha=4 / 3$ the price attains the highest level above

\footnotetext{
${ }^{1}$ For an analogous application of Dastidar's (1995) approach, see André et al. (2009).
} 
which undercutting takes place. As a consequence, $\alpha \in[0,4 / 3]$. Using (10), the individual quantity function writes:

$$
q_{b}^{*}=\frac{(2-\alpha)}{2(2+c-\alpha)} .
$$

We now turn to Cournot competition. Here the quantity in equilibrium can be easily found by maximising (3) with respect to $q$, yielding:

$$
q_{c}^{*}=\frac{1}{3+2 c}
$$

By comparing (11) with (12), it emerges that $q_{c}^{*}>q_{b}^{*}$ for:

$$
\alpha>\alpha^{*}=\frac{2(1+c)}{1+2 c} .
$$

Note that

$$
\frac{2(1+c)}{1+2 c} \leq \frac{4}{3}
$$

for $c \geq 1$. In other words, the standard effect associated with a Cournot industry, i.e., a softer competition compared to a Bertrand industry can indeed be reversed if (i) marginal cost is sufficiently high and (ii) the intensity of price competition is sufficiently low.

We are now in a position to evaluate the differences in social welfare between Bertrand and Cournot competition. According to (11) and (12), the social welfare with price and quantity competition are:

$$
W_{b}=\bar{X}-\frac{(2-\alpha)^{2}(1+c+2 v)}{2(2+c-\alpha)^{2}},
$$

and

$$
W_{c}=\bar{X}-\frac{2(1+c+2 v)}{(3+2 c)^{2}},
$$

respectively. By comparing (13) with (14), it emerges that $W_{b}>W_{c}$ for $q_{c}^{*}>$ 
$q_{b}^{*}$. The intuition is simple. A low price competition intensity lowers output production, thus increasing profits and lowering the amount of pollution and the natural resources exploited during production, but decreasing also consumer surplus. Nonetheless, the raise on the environment conditions and profits ultimately more than offsets the fall of consumer surplus in the welfare analysis. This leads to the following proposition:

Proposition 1 For all $c \geq 1$ and

$$
\alpha \in\left[\alpha^{*}, \frac{4}{3}\right],
$$

then social welfare is higher with price rather than quantity competition.

The result can be further explained by highlighting the trade-off between environmental externalities (natural resources exploitation and pollution) on the one hand and consumer surplus on the other. By evaluating each part of social welfare separately, it can be easily noted that:

$$
\begin{gathered}
X_{b}-X_{c}=\frac{2(1+c)-\alpha(1+2 c)}{(2+c-\alpha)(3+2 c)}>0, \\
E_{b}-E_{c}=\frac{w[2 c(\alpha-3)-5(2-\alpha)][\alpha(1+2 c)-2(1+c)]}{(2+c-\alpha)^{2}(3+2 c)^{2}}<0, \\
C S_{c}-C S_{b}=\frac{[2 c(\alpha-3)-5(2-\alpha)][\alpha(1+2 c)-2(1+c)]}{2(2+c-\alpha)^{2}(3+2 c)^{2}}<0,
\end{gathered}
$$

for $\alpha>\alpha^{*}$. This explains that social welfare is high with the market structure providing the lowest amount of output, because of the lower natural resources exploitation and pollution, that more than compensate the decrease in consumer surplus. 


\section{References}

[1] André, F.J., González, P. and Porteiro, N. 2009. Strategic quality competition and the Porter hypothesis. Journal of Environmental Economics and Management 57: 182-194.

[2] Dastidar, G. S. 1995. On the existence of pure strategy Bertrand equilibrium. Economic Theory 5: 9-32. 


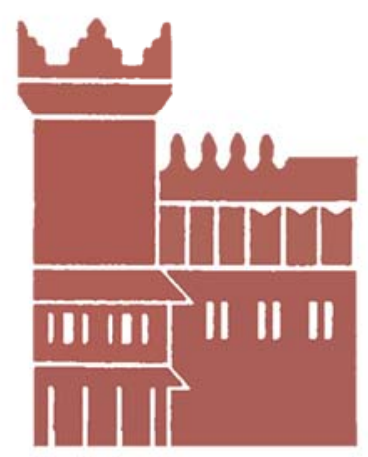

Alma Mater Studiorum - Università di Bologna DEPARTMENT OF ECONOMICS

Strada Maggiore 45

40125 Bologna - Italy

Tel. +39051 2092604

Fax +390512092664

http://www.dse.unibo.it 